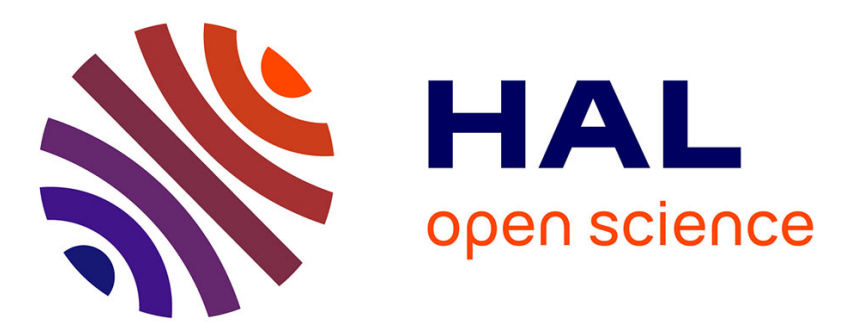

\title{
Low phase noise cryogenic amplifiers and oscillators based on superconducting resonators
}

David Chaudy, Olivier Llopis, Bruno Marcilhac, Yves Lemaître, Olivier d'Allivy Kelly, J.-M Hode

\section{- To cite this version:}

David Chaudy, Olivier Llopis, Bruno Marcilhac, Yves Lemaître, Olivier d'Allivy Kelly, et al.. Low phase noise cryogenic amplifiers and oscillators based on superconducting resonators. IEEE International Frequency Control Symposium (IFCS 2018), May 2018, Olympic Valley, CA, United States. 3p., 10.1109/FCS.2018.8597508 . hal-01868407

\section{HAL Id: hal-01868407 https://hal.science/hal-01868407}

Submitted on 5 Sep 2018

HAL is a multi-disciplinary open access archive for the deposit and dissemination of scientific research documents, whether they are published or not. The documents may come from teaching and research institutions in France or abroad, or from public or private research centers.
L'archive ouverte pluridisciplinaire HAL, est destinée au dépôt et à la diffusion de documents scientifiques de niveau recherche, publiés ou non, émanant des établissements d'enseignement et de recherche français ou étrangers, des laboratoires publics ou privés. 


\title{
Low phase noise cryogenic amplifiers and oscillators based on superconducting resonators
}

\author{
D. Chaudy ${ }^{1,3}$, O. Llopis ${ }^{1}$ \\ ${ }^{1}$ LAAS-CNRS, Université de Toulouse, CNRS \\ 7 avenue du Colonel Roche, 31031, Toulouse, France \\ dchaudy@laas.fr
}

\author{
B. Marcilhac ${ }^{2}$, Y. Lemaitre 2 , O. d'Allivy Kelly ${ }^{2}$ \\ ${ }^{2}$ Unité Mixte de Physique, CNRS, Thales, Paris-Sud \\ Université Paris-Saclay, 91767, Palaiseau, France
}

\author{
J.-M. Hode ${ }^{3}$ \\ ${ }^{3}$ Thales Defense Mission Systems \\ 75-77 Avenue Marcel Dassault, 33700, Mérignac, France
}

\begin{abstract}
A cryogenic low phase noise amplifier and an high $\mathrm{Q}$ superconductor resonator at $1 \mathrm{GHz}$ have been designed and realized. A good agreement between the measured and simulated data at $80 \mathrm{~K}$ for these two devices is observed. An all cryogenic oscillator has also been designed with the same devices on an alumina substrate. This oscillator is still under test.
\end{abstract}

Keywords- microwave oscillator, phase noise, superconductor resonator, cryoelectronics

\section{INTRODUCTION}

High Tc superconductor materials allows the design of ultra high $\mathrm{Q}$ resonators in the low microwave range. The design of an oscillator with these resonators requires an accurate modelling of the oscillating loop, which includes not only the resonator but also the transistor and the passive devices (capacitances, resistances, transmission lines). If the loop can be designed for an all-cryogenic operation, the oscillation stability will be increased. However, this is a hard task because any tuning of a device requires a time consuming process of cooling up and down the circuit. Therefore, the model of the loop elements at low temperature must be very accurate. If this step can be overcome, it could open the path to a disruptive technology. Indeed, the simulated phase noise results outperform the best commercially available $1 \mathrm{GHz}$ sources, as presented in our previous work [1].

In a first step, we present the design of a low phase noise cryogenic amplifier. This device is easier to characterize than the closed oscillating loop, and allows us to understand the problems which may appear in the oscillator design. Then, the superconducting resonator characterization and modelling is described. The integrated cryogenic oscillator is currently under test but preliminary measurements show interesting results, with a phase noise level very close to the state of the art quartz based sources..

\section{LOW TEMPERATURE AND PHASE NOISE AMPLIFIER}

Designing a low phase noise amplifier has never been an easy task and the difficulty is enhanced when all the devices are at cryogenic temperature. Every device must be carefully chosen and modelled. That is why, as presented in the last IFCS conference [1], characterization and modeling of SiGe transistors has been performed at $80 \mathrm{~K}$. An amplifier has been designed on an alumina substrate using this model. Knowing that our final goal is the realization of an oscillator at $1 \mathrm{GHz}$, we focus our designs and measurements around this frequency.

We have thus designed a single stage amplifier using a common emitter bipolar SiGe transistor. In order to stabilize the amplifier and to optimize its residual phase noise, several resistances and capacitors have been added, particularly to realize two feedback paths: one series feedback on the emitter and one parallel feedback between base and collector. The amplifier topology is presented in Fig 1.

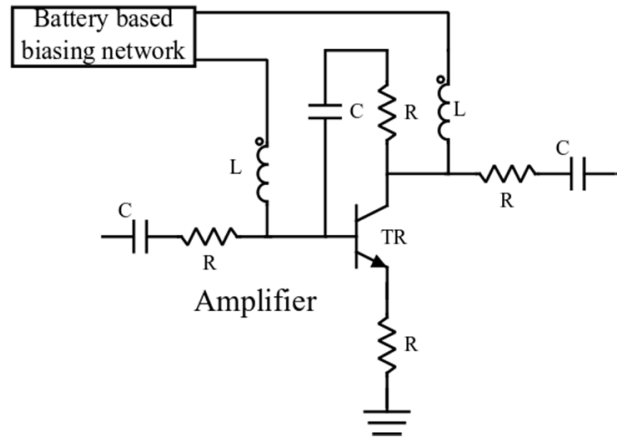

Fig. 1. $1 \mathrm{GHz}$ cryogenic amplifier.

To characterize the circuit at cryogenic temperature, the amplifier has been partially immerged in liquid nitrogen. S-parameters and noise measurement have been performed both at ambient and low-temperature. A good agreement is observed between simulations and measurements, as shown in Fig 2 for S-parameters at $80 \mathrm{~K}$. The amplifier residual phase noise has also been measured and is depicted in Fig 3. The measured phase noise floor is in the range of $-170 \mathrm{dBrad}^{2} / \mathrm{Hz}$ and is very similar to the one simulated. However, an excess noise is observed close to the carrier (below $100 \mathrm{~Hz}$ ) compared to the simulated $1 / \mathrm{f}$ phase noise level. This excess noise may be caused by vibrations and spurious signals. Indeed, the amplifier was not in a shielded housing at the time of the experiment.

This work is supported by the French MoD, Direction Générale de l'Armement (DGA) 


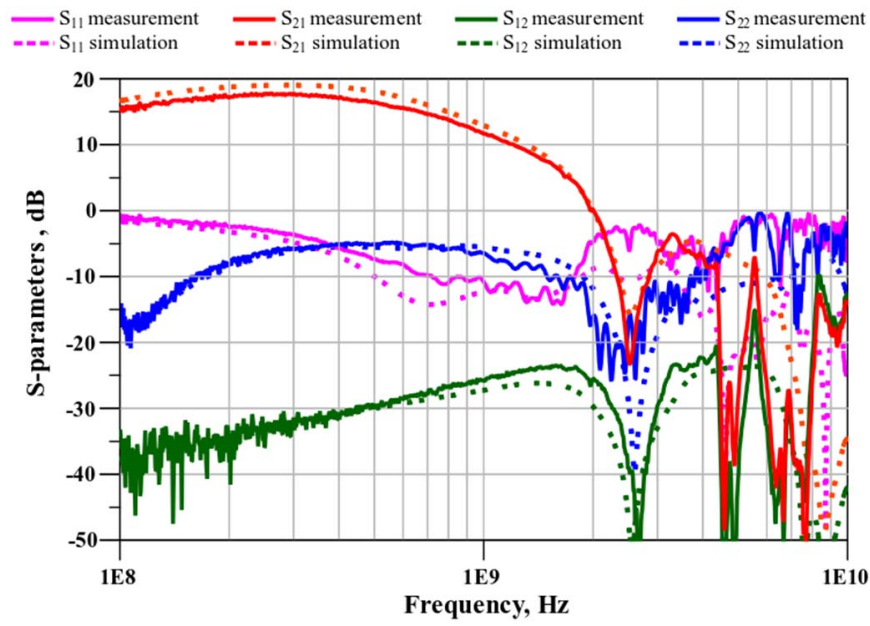

Fig. 2. Amplifier simulated and measured S- parameters curves at $\mathrm{I}_{\mathrm{C}}=5 \mathrm{~mA}$, $\mathrm{V}_{\mathrm{CE}}=2 \mathrm{~V}, \mathrm{~T}=80 \mathrm{~K}$

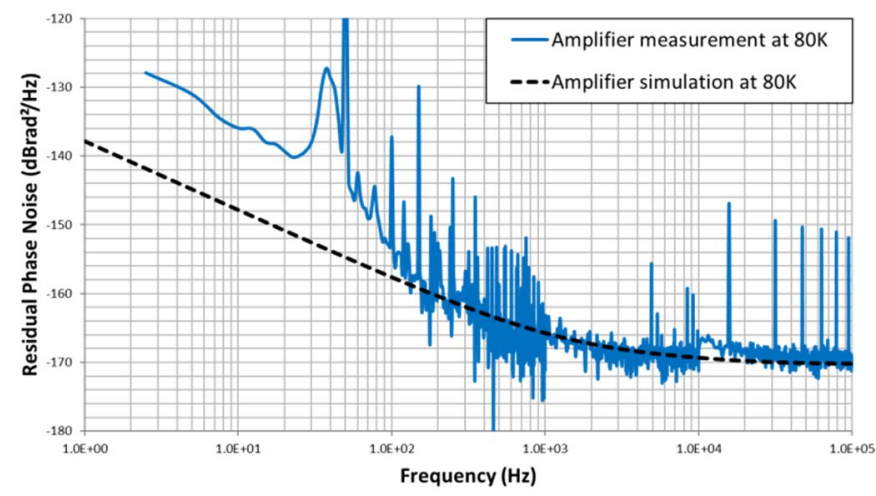

Fig. 3. Amplifier simulated and measured $1 \mathrm{GHz}$ phase noise at $\mathrm{I}_{\mathrm{C}}=5 \mathrm{~mA}$, $\mathrm{V}_{\mathrm{CE}}=2 \mathrm{~V}, \mathrm{~T}=80 \mathrm{~K}$.

The next experimental step for the amplifier is to decrease the temperature down to $60 \mathrm{~K}$. Up to now, all the measurements have been performed using liquid nitrogen, at approximately $80 \mathrm{~K}$. The use of a cryocooler will allow us to reach $60 \mathrm{~K}$. The experiment is ready as shown in Fig. 4 but measurement are still on-going.

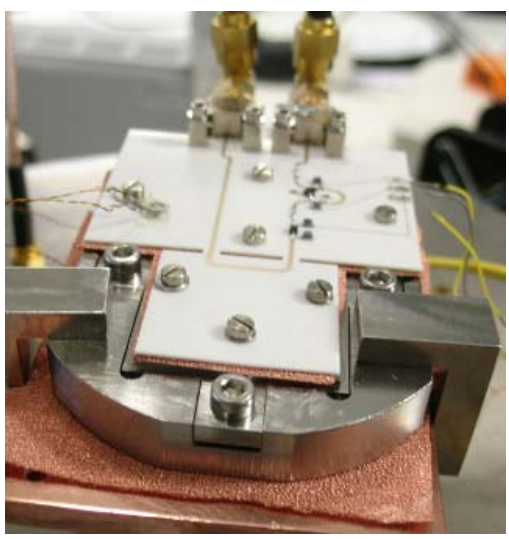

Fig. 4. $1 \mathrm{GHz}$ cryogenic amplifier on a coldfinger.

\section{HIGH-TEMPERATURE SUPERCONDUCTOR RESONATOR}

The other important part of oscillator is the resonator. In the past few years, Thales research on high-temperature superconductor has led to the development of planar resonators with quality factors in the range of 200000 near $1 \mathrm{GHz}$. After the design of a test alumina for the resonator, we have measured its frequency response at $80 \mathrm{~K}$ (Table 1,2 and Fig 5). Four interesting parameters can be extracted from those measurements: the loaded quality factor, which is 55700 at low microwave power, the input/output coupling factors and the transmission losses. From these parameters, the computed unloaded Q is 190000 , as expected. A resonator model is then extracted. In a first step, a linear black box model has been used. Then, in a second step, an electrical RLC circuit coupled with two transformers has been implemented. This model allows us to include various nonlinear elements to take into account the RF power dependence of the resonator frequency response. Indeed, as depicted in Table 1 and 2, the insertion losses and the $\mathrm{Q}$ factor are degraded at high RF power. This is a well-known behavior in superconducting cavities [2,3], due to normal current generation at high current density. This behavior has first been described by a nonlinear resistor in the RLC circuit model (1). However, a distortion of the resonance can also been observed at high power. This effect is also discussed in some papers $[3,4]$ and can be described by adding a non-linear inductor (2).

TABLE I. HTS-RESONATOR MEASURE CARACTERISTICS

\begin{tabular}{|c|c|c|c|}
\hline $\begin{array}{c}\text { Input Power } \\
(\mathbf{d B m})\end{array}$ & $\mathbf{S}_{\mathbf{2 1}}$-Max (dB) & Loaded Q & UnLoaded Q \\
\hline-30 & -3.7 & 55700 & 190000 \\
\hline-20 & -3.7 & 55500 & 190000 \\
\hline-10 & -4.2 & 51000 & 160000 \\
\hline 0 & -8.5 & 26100 & 49000 \\
\hline
\end{tabular}

TABLE II. HTS-RESONATOR SIMULATED CARACTERISTICS

\begin{tabular}{|c|c|c|c|}
\hline $\begin{array}{c}\text { Input Power } \\
(\mathbf{d B m})\end{array}$ & $\mathbf{S}_{\mathbf{2 1}}$-Max (dB) & Loaded Q & UnLoaded Q \\
\hline-30 & -3.7 & 55200 & 180000 \\
\hline-20 & -3.8 & 54500 & 180000 \\
\hline-10 & -4.6 & 48000 & 140000 \\
\hline 0 & -8.4 & 26700 & 49000 \\
\hline
\end{tabular}

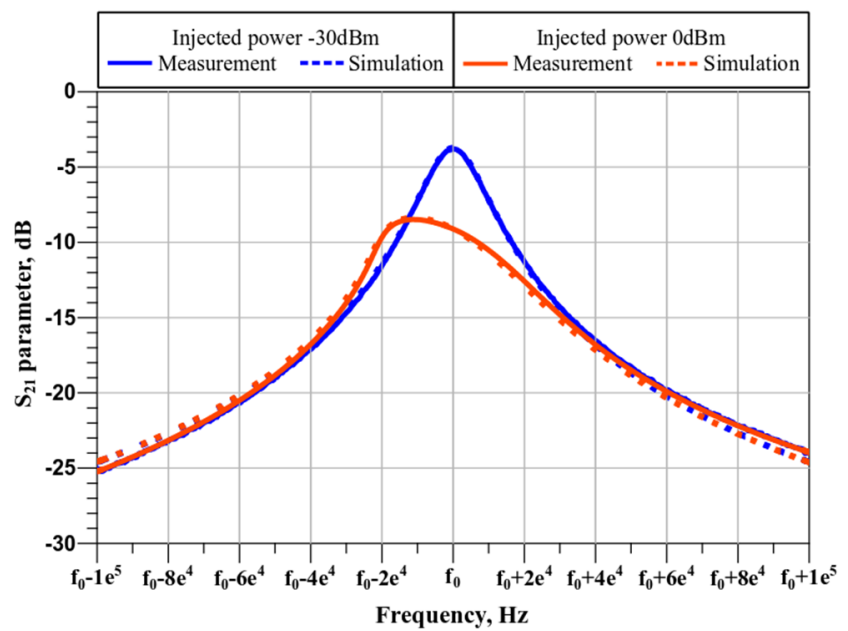

Fig. 5. Transmition parameters of an HTS-Resonator at $80 \mathrm{~K}\left(\mathrm{f}_{0} \sim 1 \mathrm{GHz}\right)$ 


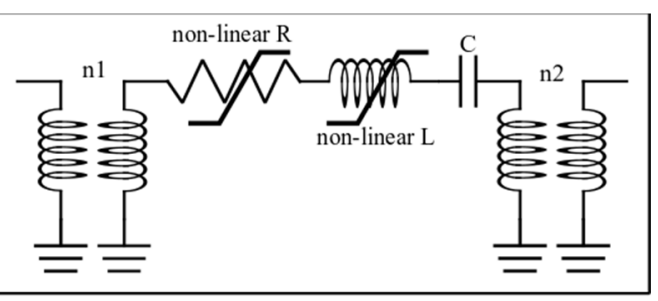

Fig. 6. Nonlinear HTS-resonator model

$$
\begin{gathered}
R=R_{0}\left(1+\alpha I^{2}+\beta I^{4}\right) \\
L=L_{0}\left(1+\gamma I^{2}\right)
\end{gathered}
$$

\section{OSCILLATOR}

These two devices, amplifier and resonator, have been assembled to realize a cryogenic oscillator (Fig. 7). All the oscillator loop is cooled down to cryogenic temperature. The only part which is not cooled, is the battery based biasing network. For all the experimental investigations, the biasing network is kept outside the cryocooler in order to provide some tuning parameters. However, in the end, it will be included on the alumina substrate so that only one wire (to connect to the battery) and one SMA cable (the RF output) will go out of the cryocooler.

The first simulations on ADS software have led to a phase noise level close to $-140 \mathrm{dBc} / \mathrm{Hz}$ at $1 \mathrm{kHz}$ offset from $1 \mathrm{GHz}$ carrier. The first experimental measurement, presented in Fig. 8, features an higher noise level than expected, close to $-130 \mathrm{dBc} / \mathrm{Hz}$ at $1 \mathrm{kHz}$ offset from carrier. After improving our model, the gap between simulation and measurement has been reduced (Fig. 8), but we still have to understand the increase of phase noise compared to the simulated one. One possible cause may be an excessive intra-cavity power in the resonator.

In any case, the oscillator performance can be improved using an higher $\mathrm{Q}$ resonator. A new resonator has thus been realized, featuring an higher loaded quality factor thanks to lower coupling factors and higher intrinsic Q, as presented in Table 3. For the moment, the modeling is still in process, but the use of this resonator may allow us to outperform the best commercially available $1 \mathrm{GHz}$ sources.

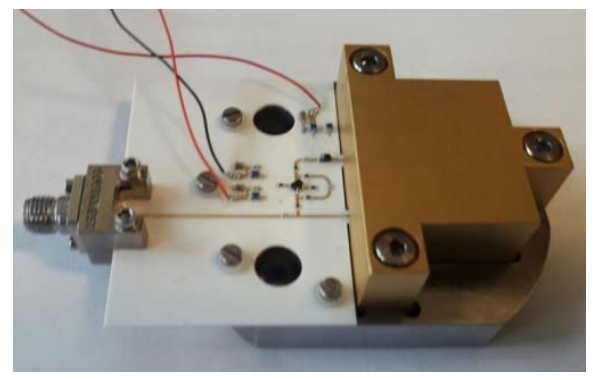

Fig. 7. $1 \mathrm{GHz}$ cryogenic oscillator

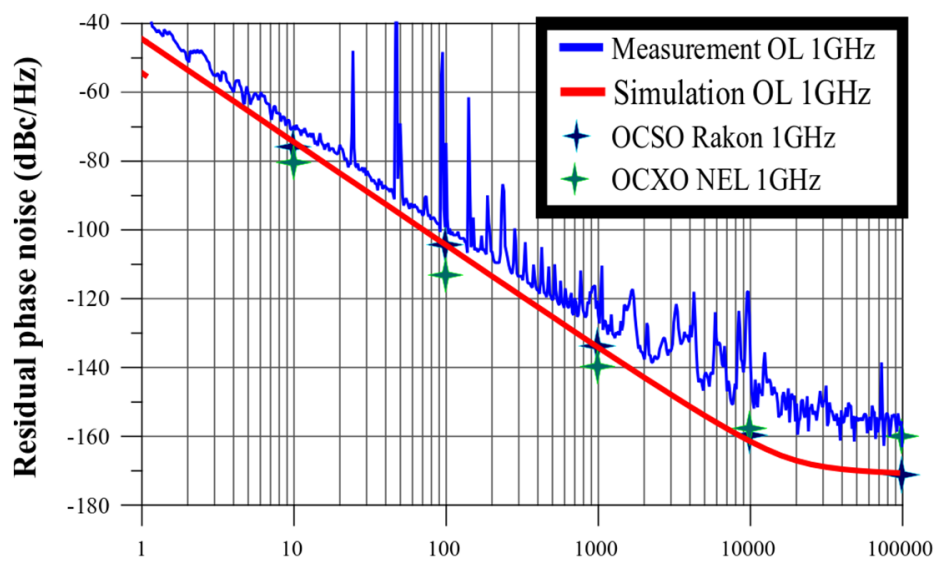

Frequency (Hz)

Fig. 8. Simulated and measured $1 \mathrm{GHz}$ oscillator phase noise at $70 \mathrm{~K}$. Comparison with two commercially available sources.

TABLE III. NEW HTS-RESONATOR MEASURED CHARACTERISTICS

\begin{tabular}{|c|c|c|c|}
\hline $\begin{array}{c}\text { Input Power } \\
(\mathbf{d B m})\end{array}$ & $\mathbf{S}_{\mathbf{2 1}}$-Max (dB) & Loaded Q & UnLoaded Q \\
\hline-30 & -6.2 & 190000 & 370000 \\
\hline-20 & -6.3 & 180000 & 350000 \\
\hline-10 & -7.0 & 160000 & 285000 \\
\hline 0 & -9.4 & 105000 & 160000 \\
\hline
\end{tabular}

\section{CONCLUSION}

Measurements and simulations of an amplifier and a superconductor resonator at $80 \mathrm{~K}$ have been presented. These devices have been assembled to realize a cryogenic oscillator. This circuit is, up to our knowledge, the first low phase noise full cryogenic oscillator at $1 \mathrm{GHz}$ using superconductor resonators. The phase noise performance is good $(-130 \mathrm{dBc} / \mathrm{Hz}$ at $1 \mathrm{kHz}$ offset from $1 \mathrm{GHz}$ carrier), even if we still do not reach exactly the state of the art of $1 \mathrm{GHz}$ sources. Further improvements are expected thanks to a new resonator and some design improvements.

\section{REFERENCES}

[1] D. Chaudy, O. Llopis, B. Marcilhac, Y. Lemaitre, O. d. Kelly and J. M. Hode, "Active devices choice and design of an all cryogenic superconductor resonator oscillator," 2017 EFTF and IEEE IFCS joint conference, Besancon, 2017, pp. 842-845.

[2] J. Kermorvant, $\mathrm{PhD}$ thesis (in french), Ecole Polytechnique, 2010.

[3] D. E. Oates, S. H. Park, D. Agassi, G. Koren and K. Irgmaier, "Temperature dependence of intermodulation distortion in YBCO: understanding nonlinearity," in IEEE Transactions on Applied Superconductivity, vol. 15, no. 2, pp. 3589-3595, June 2005.

[4] J. Wosik, L. M. Xie, R. Grabovickic, T. Hogan and S. A. Long, "Microwave power handling capability of HTS superconducting thin films: weak links and thermal effects induced limitation," in IEEE Trans. on Applied Superconductivity, vol. 9, no. 2, pp. 2456-2459, June 1999. 